These books collect, into compact individual volumes, manufacturers' data sheets and basic information on electronic components, and in addition provide, where appropriate, sections dealing with operating principles, applications and design methods. They are, in fact, compendia of electronic techniques. The annual dealing with British microminiature electronic components and assemblies is, in fact, a new book, based on the "Assemblies" section which previously formed part of the British Miniature Electronic Components Data Annual. The incroasing use of thin-film solid-state units and of printedcircuit techniques has made it necessary to devote more space to miniature and microminiature electronic assemblies.

This series of annuals forms a source of technological data and information on electronic techniques which is remarkably comprehensive. The books are well indexed. and the information therefore readily accessible. The series forms a most valuable day-to-day reference for research workers and designers concerned with electronic equipment, and should serve a most useful purpose when placed, perhaps, in the research laboratory or workshop rather than in tho library.

J. Greig

\section{Controlled-Potential Analysis}

By Garry A. Rechnitz. (International Series of Monographs on Analytical Chemistry, Vol. 13.) Pp. 85. (Oxford, London, New York and Paris: Pergamon Press, 1963.) $35 s$.

$\Delta \mathrm{N}$ electrolysis that is carried out with the potential A of the working eloctrode fixed at a selected value is a controlled-potential electrolysis. When such an electrolysis is used in analysis it is controlled-potential analysis. Most commonly in analysis, the substance being analysed is determined by weighing the amount deposited at the working electrode, that is, controlled-potential electrogravimetric analysis. Less commonly, the amount is determined by measuring the quantity of electricity that passes during the electrolysis, that is, controlled-potential coulometry.

It is a pity that the author of this monograph has, throughout the book and especially in Chapter 1, "Introduction", used these terms at random. In fact, after reading the book, the reader is left wondering whether the author intended to write about controlled-potential analysis generally or about controlled-potential coulometry in particular.

Chapter 2, "Theory", deals with the elementary theory of controlled-potential coulometry and its application to analysis and kinetic investigations. Secondary reactions are also discussed. In Chapter 3, "Apparatus and Techniques", the ideal characteristics of potentiostats are listed and described, and five commercial instruments are appraised. Current integration by graphical, mechanical and electronic means, and the electrodes and electrolysis systom, are discussed. In the final chapter, "Analytical Applications", some 35 elements are treated togother with the alkali metals, the rare earths and the halides.

This work is intended for practising analytical chemists. Many would find it, in spite of the confusion of terms, a ready source of information on controlled-potential analysis.

J. F. C. TYLER

\section{Teaching Machines and Programming}

Edited by K. Austwick. Pp. vii + 201. (Oxford, London and New York: Pergamon Press, 1964.) $42 s$.

THIS book deals with a relatively new venture in the

field of instruction. Programmed learning is the label now accepted for a group of techniques in which subject matter is presented to the individual in an orderly series of 'steps', with future progress made in some way dependent on past success, and in which the individual can be informed about the success with which he has tackled one step before proceeding to the next. Programme presentation can vary from the traditional live teacher to time-sharing computers, with simple pencil and paper devices and more complex electro-mechanical machines in between. Programmes may be written to cover very small parts or the whole of a syllabus.

By the beginning of 1963 , when the six contributors wrote their chapters, industry, schools, services and universities on both sides of the Atlantic had accepted programmed learning as a useful medium in an era where demand for instruction had outstripped supply. The questions now raised are centred primarily on ways and means: Under what conditions, and for what kind of subject-matter, is programmed learning suitable when judged by a number of criteria? Teaching Machines and Programming answers some of these questions as well as giving the necessary background information. The writers have all had practical and research experience in programmed learning in Britain, and one common theme is the extent to which laboratory and real life merge in this field.

In Kay's searching introduction no stitches are dropped and no punches pulled. Annet's chapter includes valuable cost-accounting. Sime stresses the use of teaching machines as a research tool. Pask states the case for completely automated teaching. Reid's robust chapter is an enjoyable exposition of Skinner's ideas, pure and applied. The editor discusses the possible uses of automation in schools.

The decision to make the chapters self-contained produces much repetition of general concepts. Some of the plates are poor, and many give little idea of scale. The index and references are good.

J. A. LeONARD

\section{Comprehensive Biochemistry}

Edited by Prof. Marcel Florkin and Prof. Elmer H. Stotz. Vol. 15: Group-Transfer Reactions. Pp. xii +246 . (Amsterdam, London and New York: Elsevier Publishing Company, 1964.) 70s.

COMPREHENSIVE Biochemistry is one of a section of five volumes devoted to an examination of enzyme catalysis at the molecular level. The reader must not expect, therefore, to be presented with an integrated account of metabolic processes; this will presumably follow in a later section of this treatiso. Six chapters describe the present state of our knowledge of those biochemical reactions in which a group is transferred from one substrate or co-enzyme to another. The transferred group may be as small as a methyl group or as large as an oligosaccharide residue. The reactions which are discussed in this volume include the transfer of formyl, hydroxymethyl and methyl groups (S. Harvey Mudd and G. L. Cantoni); reactions catalysed by transketolase and transaldolase (B. L. Horecker); transfer of acyl groups (P. Goldman and P. R. Vagelos); the transfer of glycosyl groups (L. Glaser); transaminations and decarboxylations in which vitamin $B_{6}$ is implicated (B. M. Guirard and E. E. Snell); and the transfer of phosphate groups catalysed by phosphokinases and phosphomutases (R. K. Crane, C. F. Cori and D. H. Brown).

Reading this volume and the others in this series dealing with biochemical reaction mechanisms emphasizes the dearth of our knowledge about the early stages of an enzymo-catalysed reaction. Investigations of pre-stoadystate kinetics and the conformational changes induced in an enzyme by the approach of a substrate are virtually unexplored territories. Two features of Comprehensive Biochemistry must be commended. In contrast to some of the earlier parts of the treatise, this volumo is not badly out of date; there are a few references as recent as 1963. Secondly, several of the authors have included a lot of detailed information in tabular form. This simplifies the reading for both the expert and the person who requires a background of modern enzymology. D. T. ELMORE 